\title{
The Production-Oriented Approach: Moving Forward
}

\author{
Rod Ellis \\ Curtin University, Australia
}

In this extremely well-organized seminar various aspects of the POA were presented in the morning while in the afternoon a group of invited evaluators discussed the approach. I would like to thank the organizers of the seminar for inviting me to join the panel of evaluators and to congratulate them on what proved an enlightening and rewarding experience.

Various points were raised in the afternoon session by the invited evaluators. I will focus on the points that I myself raised. In making these points, however, I would like to emphasize that my overall impression of the POA was that it was a very well-thought out course with a strong theoretical basis and some interesting teaching materials. I particular liked making the starting point for each unit a production activity designed to make students aware of their cognitive and linguistic limitations in order to motivate their attention when performing the subsequent input-based enabling activities.

The following are the specific points I raised:

\section{Appropriate assessment}

My understanding is that it is customary for all students to take a test at the end of a semester's course and that this test is used to grade students' performance on the course. I understand that design of the test may lie outside the control of the teacher teaching a course. The danger here is that the end of semester test does not adequately assess the abilities and skills that the POA is designed to develop. I was pleased to hear that up to $40 \%$ of students' final marks were based on a portfolio of activities completed during the course. However, if the course materials are not seen to closely match the methods of assessment, students' attitudes to the course may be adversely affected. Ideally, instructors of a course need to be able to determine how their course is assessed. Perhaps the developers of the POA course materials can provide guidance on how this can be achieved. Incompatibility between instructional objectives and methods of assessment is probably the most influential factor affecting the successful uptake of innovations. I am aware, 
however, of the institutional constraints that exist regarding assessment in China and that the POA team is limited in what it can achieve.

\section{Teacher training}

The POA materials have been carefully trialled, published and now distributed to colleges. Perhaps at this stage then the efforts of the hard-working POA team might best be directed towards the design and implementation of a teacher training course. The success of the materials may well depend on the availability and quality of the teacher training provided. Such a course should follow the principles and structure of the POA teaching materials. That is, it should not take the form of a set of lectures about POA but involve teachers in the same sequence of activities found in the course itself - that is, teachers should be invited to complete the same motivating, enabling and assessment activities as their students and to reflect on teaching strategies that are effective for implementing them. The course should also address specific problems - which prior observation of POA classes has revealed are likely to occur - again adopting a problem-solution approach (i.e. starting by making teachers aware of a problem followed by activities that guide them to its solution).

\section{Personal expression}

By and large to POA materials are centred on enabling students to perform tasks whose content is to a considerable extent prescribed by the teaching materials. My impression is that there is little room for students to talk about their own personal experiences. However, there are some very powerful reasons for building in activities where students talk about content of their own choice. Activities where students are free to talk about themselves or topics that personally interest them are likely to be motivating. In small group activities, for example, students are more likely to be responsive to what other students are saying if the talk is personal in nature. In general, students are better motivated to talk about student-generated than teacher-generated or materials-generated content. A further reason for including opportunities for students to engage in personal expression is that it provides teachers with evidence of whether students are able to make use of the thematic and linguistic content of a unit in a new context - i.e. whether transfer of training has occurred and whether, as a result, true (rather than just reproductive) proficiency is developing.

I believe that it would be possible to add an extension activity at the end of a unit so as to create a context where students can use both their existing linguistic resources and the new language they have learned from the unit to talk about a topic or event of personal significance to them. For example, if the theme is 'Kindness and Indifference' (Unit 4 in Book 2), students could be asked to recount an incident that they had observed and people's reactions to it. 


\section{The importance of social interaction}

In my reading about the POA (e.g. Wen, 2016) I was struck by the omission of reference to the role of social interaction in language learning. The POA draws primarily on 'input' and 'output' without clearly acknowledging that in primary forms of communication these occur within social interaction. Whether in cognitive-interactionist or sociocultural SLA, emphasis is placed on social interaction as the site either where input and output originate or in which learning actually occurs. There is now a wide body of research that demonstrates the importance of interaction for L2 acquisition, the specific features of interaction that are important, and the kinds of activities that are likely to give rise to these features. Thus a question I would like to see answered - and I do not think it was during the seminar - is to what extent the POA materials foster acquisition-rich interaction. Do they promote the negotiation of meaning? Is there any negotiation of form? Do learners engage in language-related episodes when they perform activities? I would want to know to what extent the activities result in a variety of exchange types or whether the ubiquitous initiate-response-feedback exchange dominates interaction in the POA classroom in the same way it does in so many classrooms. Do students get to ask questions as well as respond to them? What opportunities are there for focus-on-form while students are speaking? One of the primary goals of task-based language teaching is to ensure that the instructional activities afford opportunities for the kinds of interaction that have been shown to foster acquisition. POA is not task-based language teaching but ideally it needs to ensure that the materials result in contexts where interaction can do its work for acquisition and in this respect could draw on some of the principles of TBLT.

\section{Evaluating the materials}

There was some discussion among members of the panel about how best to set about evaluating the POA materials. I believe that evaluation methods should be eclectic, including the following:

- Descriptive studies of the classroom processes that result from the use of the materials. Such studies can address to what extent specific instructional activities results in the behaviours and outcomes they were designed to elicit. I have called this a 'response-based evaluation' (Ellis, 1997). In addition they can examine to what extent the activities result in the behaviours and outcomes that theory claims are important for acquisition (e.g. whether negotiation of meaning/form occurs; whether there is opportunity for student initiation). A particular focus of a descriptive evaluation could be on whether students make use of the new language introduced in the enabling activities in the final production activity. Descriptive studies are important because they go inside the 'black box' of the classroom to document what actually happens when the materials are used. 
- Self-report studies. These use surveys or interviews that elicit how the students and teachers responded to the materials. These student- and teacher-based evaluations are probably the most common form of evaluation. They are helpful but perhaps also limited especially if they are carried out only once at the end of a course. Self-report studies do not tell as much about students' and teachers' actually responses to the materials only what they are prepared to say about the activities. They are perhaps most helpful if they focus not on a complete course but on specific instructional activities and are conducted shortly after these activities have been completed.

- Product-based studies. These focus on whether any learning has taken place as a result of using the materials. The POA course aims address both students' development as moral and socially responsible citizens and their language development. Thus a product-based evaluation will need to collect evidence to show that the POA materials have had an impact on both. This will necessitate pre- and post-testing. Product-based studies are challenging because it is difficult to develop instruments that are sensitive enough to capture changes that can occur over a single semester. They are important, however, as ultimately language education is about instigating change so we need to know if a particular instructional approach has been successful in this respect.

A full evaluation would include all three types of studies and, given the time-consuming nature of programme evaluation, ideally needs to be carried out as a team. Individual doctoral students, for example, could be assigned to carry out a particular type of evaluation study.

During the seminar I also suggested that there is a need for a comparative-method study - a view not endorsed by other members of the panel. Despite the difficulties of designing such a study, I believe there is a need for one. If a new set of instructional materials has been developed (at great expense) we need to ultimately find out whether these materials are more effective that an existing set of materials. There are examples of well-designed comparative method studies that could serve as a basis for designing a study (see, for example, Shintani's (2015) comparative study of PPP and TBLT). A comparative method study, of course, would need to incorporate a descriptive element, a self-report element and a product-based element.

\section{References}

Ellis, R. (1987). The empirical evaluation of language teaching materials. English Language Teaching Journal, 51 (1), 36-42.

Shintani, N. (2016). Input-based tasks in foreign language instruction for young learners. Amsterdam: John Benjamins.

Wen, Q. (2016). The production-oriented approach for teaching university students English in China. Language Teaching. downloaded from https://doi.org/10.1017/S026144481600001X 


\section{About the author}

Rod Ellis is a Research Professor in the School of Education at Curtin University, Australia. For the last eight years he has served as a visiting professor at Shanghai International Studies University as part of China's Changjiang Scholars Program. His research focuses on second language acquisition and its application to language teaching. Email: r.ellis@auckland.ac.nz 
Reproduced with permission of copyright owner. Further reproduction prohibited without permission. 